\title{
Comparing Perimenstrual and Nonperimenstrual Migraine Attacks Using an e-Diary
}

Daphne S. van Casteren, MD, PhD, * Iris E. Verhagen, MD,* Britt W.H. van der Arend, MD, Erik W. van Zwet, PhD, Antoinette MaassenVanDenBrink, PhD, $\dagger$ and Gisela M. Terwindt, MD, PhD $\dagger$

Neurology ${ }^{\circledR}$ 2021;97:e1661-e1671. doi:10.1212/WNL.0000000000012723

\section{Abstract}

\section{Background and Objectives}

Endogenous and exogenous female sex hormones are considered important contributors to migraine pathophysiology. Previous studies have cautiously suggested that perimenstrual migraine attacks have a longer duration and are associated with higher disability compared to nonperimenstrual attacks, but they showed conflicting results on acute therapy efficacy, pain intensity, and associated symptoms. We compared perimenstrual and nonperimenstrual migraine attack characteristics and assessed premenstrual syndrome (PMS) in women with migraine.

\section{Methods}

Women with migraine were invited to complete a headache e-diary. Characteristics of perimenstrual attacks and nonperimenstrual attacks were compared. The primary outcome was attack duration. Secondary outcomes were headache intensity, accompanying symptoms, acute medication intake, and pain coping. Mixed effects models were used to account for multiple attacks within patients. PMS was assessed in patients without hormonal contraceptives. Subgroup analyses were performed for women with menstrually related migraine (MRM) and nonmenstrually related migraine (nonMRM) and women with a natural menstrual cycle and women using hormonal contraceptives.

\section{Results}

A representative group of 500 participants completed the e-diary for at least 1 month. Perimenstrual migraine attacks $(n=998)$ compared with nonperimenstrual attacks $(n=4097)$ were associated with longer duration (20.0 vs 16.1 hours, $95 \%$ confidence interval $0.2-0.4$ ), higher recurrence risk (odds ratio [OR] 2.4 [2.0-2.9]), increased triptan intake (OR 1.2 [1.1-1.4]), higher headache intensity (OR $1.4[1.2-1.7]$ ), less pain coping (mean difference $-0.2[-0.3$ to $-0.1]$ ), more pronounced photophobia (OR $1.3[1.2-1.4]$ ) and phonophobia (OR 1.2 [1.1-1.4]), and less aura (OR 0.8 [0.6-1.0]). In total, 396/500 women completed the diary for $\geq 3$ consecutive menstrual cycles, of whom 56\% (221/396) fulfilled MRM criteria. Differences in attack characteristics became more pronounced when focusing on women with MRM and women using hormonal contraceptives. Prevalence of PMS was not different for women with MRM compared to non-MRM (11\% vs $15 \%)$.

\section{Discussion}

The longer duration of perimenstrual migraine attacks in women (with MRM) is associated with higher recurrence risk and increased triptan use. This may increase the risk of medication overuse and emphasizes the need to develop female-specific prophylactic treatment.

\author{
Correspondence \\ Dr. Terwindt \\ G.M.Terwindt@lumc.nl
}

\section{RELATED ARTICLE}

\section{Patient Page}

Differences Between Perimenstrual Migraine Attacks and Migraine Attacks at Other Times of the Cycle

Page e1753

\section{MORE ONLINE}

CME Course

NPub.org/cmelist 


\section{Glossary}

ACOG = American College of Obstetricians and Gynecologists; $\mathbf{C I}=$ confidence interval; $\mathbf{C S D}=$ cortical spreading depression; DRSP = Daily Record of Severity of Problems; DSM-IV = Diagnostic and Statistical Manual of Mental Disorders, 4th edition; ICHD-3 = International Classification of Headache Disorders-3; LUMINA = Leiden University Migraine Neuro-Analysis; $\mathbf{M R M}=$ menstrually related migraine; $\mathbf{O R}=$ odds ratio; $\mathbf{P M S}=$ premenstrual syndrome.

Endogenous and exogenous female sex hormones are considered important contributors to migraine pathophysiology. Migraine prevalence strongly increases in women after menarche, and attack frequency notably changes during hormonal milestones, such as pregnancy and menopause. ${ }^{1,2}$ Menstruation is the most reported migraine trigger factor in women. ${ }^{3}$ The exact underlying pathophysiologic mechanism is suggested to be the drop in estrogen level prior to the menstruation leading to increased brain excitability and triggering the trigeminovascular system. ${ }^{4-6}$ The rate of estrogen decline seems important in attack provocation. ${ }^{7}$ Although previous (small) diary-based studies cautiously suggested that perimenstrual migraine attacks have a longer duration and are associated with higher disability compared to nonperimenstrual attacks, they showed conflicting results on acute therapy efficacy, pain intensity, and associated symptoms. ${ }^{8-11}$

Many patients with migraine report prodromal symptoms before the headache phase. It is hypothesized that a mechanism of subcortical and diencephalic brain activation at the start of an attack and prior to the headache, including that of basal ganglia, hypothalamus, and thalamus, causes a topdown effect on brainstem structures involved in trigeminovascular nociception. ${ }^{12}$ Interestingly, the affective, behavioral, and physical symptoms belonging to the premenstrual syndrome (PMS) show many similarities with the prodromal migraine phase. ${ }^{13-15}$ Previous studies suggested an increased risk of migraine in women with PMS of approximately $60 \% .{ }^{15,16}$ Due to the strictly defined temporal relationships between menstrual related migraine, PMS, and menstruation, prospective diaries are needed to reliably confirm diagnoses. ${ }^{17,18}$

With this prospective electronic diary (e-diary) study, we aimed to study perimenstrual and nonperimenstrual migraine attack characteristics in a large group of women with migraine. Furthermore, we assessed PMS in women fulfilling criteria of menstrually related migraine (MRM) and women in whom attacks were not menstrually related (non-MRM).

\section{Methods}

\section{Study Design and Population}

This study is a longitudinal prospective cohort study among women with migraine conducted between February 2019 and October 2020.

\section{Participants' Background Information}

Dutch patients with migraine aged $18-80$ years were recruited by the Leiden Headache Center and our research website (lumc.nl/hoofdpijn). They were considered eligible after a 2-step inclusion process using validated questionnaires via the dedicated Leiden University Migraine Neuro-Analysis (LUMINA) website. Patients were first asked to fill out a validated web-based screening questionnaire with a sensitivity of 0.93 and specificity of $0.36 .{ }^{19}$ Patients who fulfilled the screening criteria were sent a validated web-based extended migraine questionnaire $^{20}$ based on International Classification of Headache Disorders-3 (ICHD-3) criteria. ${ }^{21}$ The specificity of the second questionnaire was 0.95 and sensitivity was $0.45 .^{20}$ We consider the cohort a well-defined web-based cohort; $87 \%$ of the participants were previously diagnosed with migraine by a physician. Final diagnoses were made based on the ICHD-3 criteria $^{21}$ after a clinical interview by a neurology resident with consultation of a headache specialist or a researcher with headache expertise.

Pregnant, breastfeeding, and postmenopausal women were excluded from participation. In addition, women using continuous sex hormonal therapies were excluded (e.g., hormone-releasing intrauterine device, progesterone-only pill, etonogestrel implant or medroxyprogesterone injection for contraception, or oral estradiol/dydrogesterone as hormone replacement therapy to reduce climacteric symptoms). No women were using combined hormonal patches or vaginal rings for contraception. When using combined oral contraceptives, patients had to be willing to insert a pill-free period every month. Women with a current gynecologic malignancy or a history of oophorectomy or hysterectomy were excluded.

\section{Standard Protocol Approvals, Registrations, and Patient Consents}

The study was approved by the medical ethics committee of Leiden University Medical Center (METC number P18.181). All participants provided written informed consent.

\section{e-Diary}

For this study, we used our self-developed time-locked e-diary. ${ }^{22}$ Patients received a daily link at 9.00 AM by email to access the e-diary covering the previous 24 hours (from midnight to midnight), consisting of 6-31 questions depending on the absence or presence of headache including its detailed characteristics and associated symptoms (1 sided/ throbbing/intensity/increasing with physical activities/ photophobia/phonophobia/nausea/vomiting/pain coping), presence of aura symptoms including characteristics and 
duration, acute and prophylactic medication, and menstruation. Up to 5 additional questions were asked depending on the absence or presence of menstruation, including intensity of the bleeding, menstrual pain, and associated use of analgesics. Questions regarding the presence of PMS based on the Daily Record of Severity of Problems (DRSP) scale were incorporated in the e-diary. ${ }^{17}$ The DRSP scale consists of 21 items regarding affective and physical symptoms and 3 items on associated functional impairment, all rated on a 6-point severity scale. If an e-diary was not completed at 11:00 $\mathrm{AM}$, an alert with the same link was sent by text message as reminder. An additional check on e-diary adherence was performed twice a week, and if necessary, a final reminder was sent by email to avoid missing e-diaries. No adjustments could be made after completion of an e-diary. When e-diaries were not completed, they were time-locked after 6 days. We aimed to collect data for 1-3 menstrual cycles per patient. Patients who completed the e-diary for less than 1 month were excluded. Missing days were considered headache-free. Single days with spotting or bleeding were not considered to belong to a menstruation period. In patients with a natural menstrual cycle, menstrual bleedings with a gap up to a maximum of 3 days were interpreted as 1 continuous menstruation. Finally, cycle lengths with a duration $<14$ days were visually inspected and adjusted when accidently wrong answers were suspected $(\mathrm{n}=27)$.

An automatic algorithm calculated for each day whether it was a headache day. A headache day was defined as a day with a headache lasting for at least 1 hour or for which acutely acting medication (analgesics or triptans) was used. If a headache was present, the algorithm verified diagnostic criteria for migraine according to ICHD-3 criteria. ${ }^{21}$ Days on which a triptan was used or days with aura symptomatology lasting 5-60 minutes were also interpreted as migraine days. By definition, each migraine day was also considered a headache day. Headache days not fulfilling criteria of migraine days were labeled as nonmigrainous headache days.

\section{Outcome Measures}

All registered migraine attacks were divided into perimenstrual attacks and nonperimenstrual attacks according to the ICHD-3 criteria. ${ }^{21}$ MRM was defined based on the ICHD-3 criteria as migraine attacks that occur between day 1 of menstruation \pm 2 days, during at least 2 of 3 menstrual cycles, while additional attacks may occur at other times of the cycle. $^{21}$ The primary outcome was the difference in migraine attack duration in hours between perimenstrual attacks and nonperimenstrual attacks. A migraine attack that was temporarily remitted, regardless of the intake and effectivity of acutely acting medication, and then recurred within 24 hours was considered as 1 attack. Time in between was also included in the attack duration. The secondary outcomes were differences in attack duration when migraine-free periods of $<48$ hours are included in the duration, maximum headache intensity (rated as mild, moderate, or severe), associated symptoms (i.e., photophobia, phonophobia, nausea, vomiting, all rated as mild, moderate, or severe), aura symptoms, use of acute medication (analgesics/triptans), 2-hour headache response, 2-hour pain-free response, recurrence of migraine within 24 hours, recurrence of migraine within 48 hours, and pain coping (rated on a visual analogue scale from 0.0 to 10.0; lower score means less coping). A 2-hour headache response was defined by a reduction of moderate or severe predose headache to mild or no pain 2 hours after the intake of a triptan. A 2-hour pain-free response was defined by a reduction of moderate or severe predose headache to no pain 2 hours after the intake of a triptan. Recurrence was defined as migraine that recurred after the intake of a triptan among patients who were pain-free 2 hours postdose. Diagnosis of chronic migraine, medication overuse headache, and the use of oral combined contraceptives were considered potential confounders for all outcomes and were therefore included as covariates in all statistical models. The use of analgesics due to menstrual pain was in addition considered a potential confounder for differences in headache intensity and for differences in the use of analgesics during migraine attacks. Chronic migraine was defined as a mean of $\geq 15$ headache days per month, from which $\geq 8$ days fulfilled criteria of a migrainous headache or triptan intake. ${ }^{21}$ Medication overuse was defined based on the average use of acutely acting treatment (analgesics $\geq 15$ days per month or triptans $\geq 10$ days per month or a combination of analgesics and triptans $\geq 10$ days per month). ${ }^{21}$

PMS was assessed in women with MRM and non-MRM who were not using combined oral contraceptives. A minimum of 2 registered menstrual cycles is required to reliably assess PMS. ${ }^{17}$ This criterion was automatically met because only those women who completed E-diaries during 3 menstrual cycles, which was needed to assess criteria of MRM, were included in the analyses on PMS. There are multiple criteria available for PMS, and there is not one widely accepted and universally used option. Furthermore, existing criteria for PMS have not been validated in women with migraine specifically, while overlapping symptomatology among PMS, the premonitory phase of migraine attacks, and depression and anxiety, which are strongly associated with migraine, further complicates the diagnosis in women with migraine. In this study, we used questions from the DRSP scale to diagnose PMS, which were inquired in the e-diary on a daily basis. The DRSP scale consists of 21 items regarding affective and physical symptoms and 3 items on associated functional impairment, all rated on a 6-point severity scale. ${ }^{17}$ We calculated the mean total DRSP symptom score during the late luteal phase (defined as the 5 days prior to the onset of menstruation) and the midfollicular phase (defined as 6-10 days from the start of menstruation). In addition, the mean total functional impairment score was calculated for the late luteal phase and the midfollicular phase. Subsequently PMS was defined as (1) a $30 \%$ higher mean total DRSP symptom score in late luteal phase compared to midfollicular phase and (2) higher mean total functional impairment score in late luteal phase compared to midfollicular phase. This definition was 
adapted from the DRSP, DSM-IV, and American College of Obstetricians and Gynecologists (ACOG) criteria with a few adjustments. ${ }^{23,24}$ Due to the strong association between migraine and depression, exclusion of patients with depression would lead to an unrepresentative group of patients with migraine. ${ }^{25-27}$ Thus, women with depressive or anxiety symptoms were not excluded. Secondly, according to DSMIV criteria, premenstrual symptoms should remit completely following the onset of menstruation. This criterion was also dropped, as similar symptoms could be attributed to (the premonitory phase of) a migraine attack, and could therefore still occur after the onset of menstruation.

\section{Data Analysis and Statistics}

Descriptive statistics were used to present characteristics of the included women with migraine. To account for the correlation between the repeated observations of the same patient, we used mixed effects regression models with a random intercept per patient for all our analyses. The relation between migraine attacks and menstruation and potential confounders were added as fixed effects. Migraine attack duration was log transformed to achieve a normal distribution. Linear mixed effects models were used to assess the difference in continuous outcome measures (i.e., attack duration and pain coping) between perimenstrual migraine attacks and nonperimenstrual migraine attacks. Ordinal logistic mixed effects models were used to investigate differences in ordinal outcome measures (i.e., headache intensity, nausea, vomiting, photophobia, and phonophobia) and logistic mixed effects models were used to assess differences in binary outcome measures (i.e., aura symptoms, use of analgesics, use of triptans, 2-hour headache response, 2-hour pain-free response and recurrence of migraine). Subgroup analyses were performed by diagnosis (MRM and non-MRM), based on completed E-diaries during 3 menstrual cycles, which was needed to assess criteria of MRM. In addition, women using hormonal contraceptives and women with a natural menstrual cycle were analyzed separately. Two-sided $p$ values $<0.05$ were considered statistically significant. All analyses were performed in $\mathrm{R}$, version 3.6.1.

\section{Data Availability}

Data not published within the article will be shared by request from an investigator.

\section{Results}

As part of our LUMINA program, a total of 3,596 women were invited to participate, of whom 901 women indicated they were interested and potentially met the inclusion criteria. Of these, 518/901 started with the e-diary, and 500/901 completed the e-diary for at least 1 month between February 2019 and October 2020 (Figure 1). Few women $(\mathrm{n}=45)$ prematurely ended their participation due to the start of continuous sex hormonal therapy or pregnancy or personal (health-related) circumstances. Overall, e-diary adherence was high, with 396 women who completed E-diaries for at least 3 menstrual cycles, 41 women who completed E-diaries for 2 menstrual cycles, 34 women who completed E-diaries for 1 menstrual cycle, and 29 women who did not menstruate during e-diary registration. Baseline characteristics of the study population are shown in Table 1 . The study population that was included $(\mathrm{n}=500)$ was representative for the total group of 3,596 invited women, regarding migraine, medication use, and comorbid depression (data not shown).

\section{Primary Outcome}

The median attack duration was 20.0 hours for perimenstrual migraine attacks and 16.1 hours for nonperimenstrual migraine attacks when migraine-free periods of less than 24 hours were included in the duration (Figure 2 and Table 2). The average attack duration of perimenstrual attacks was $35 \%$ longer compared to nonperimenstrual attacks after correction for possible confounders $(\beta=0.30,95 \%$ confidence interval [CI] 0.2-0.4, $p<0.001)$.

\section{Secondary Outcomes}

The average attack duration of perimenstrual attacks was $84 \%$ longer than the duration of nonperimenstrual attacks after correction for possible confounders when migraine-free periods of less than 48 hours were included in the duration $(\beta=0.61,95 \%$ CI 0.5-0.7, $p<0.001$ ) (Figure 2 and Table 2 ). The 2-hour headache and pain-free response after triptan intake were not different between perimenstrual and nonperimenstrual attacks, but perimenstrual attacks recurred more often than nonperimenstrual attacks (odds ratio [OR] 2.4, 95\% CI 2.0-2.9, $p<$ 0.001 ). Perimenstrual migraine attacks were also more often associated with triptan intake (OR 1.2, 95\% CI 1.1-1.4, $p=$ 0.004). Pain coping (rated 0-10) was lower (adjusted mean difference $-0.2,95 \% \mathrm{CI}-0.3$ to $-0.1, p<0.001$ ) and headache intensity (rated mild/moderate/severe) higher during perimenstrual migraine attacks compared to nonperimenstrual attacks (OR 1.4, 95\% CI 1.2-1.7, p < 0.001) (Figure 3). Associated symptoms of photophobia and phonophobia were more pronounced, but nausea and vomiting were not (Table 3). No difference was found regarding aura (Table 3 ).

\section{Subgroup Analyses: MRM and Non-MRM}

In women with MRM, the average attack duration of perimenstrual attacks was $44 \%$ longer compared to nonperimenstrual attacks when migraine-free periods of less than 24 hours were included in the duration $(\beta=0.36,95 \% \mathrm{CI}$ $0.3-0.4, p<0.001)$ and $107 \%$ longer when migraine-free periods of less than 48 hours were included in the duration ( $\beta$ $=0.73,95 \%$ CI $0.6-0.8, p<0.001)$. In women with nonMRM, perimenstrual attacks were only $13 \%$ longer when migraine-free periods of less than 24 hours were included in the duration $(\beta=0.12,95 \% \mathrm{CI}-0.04-0.3, p=0.137)$ and $30 \%$ longer when migraine-free periods of less than 48 hours were included in the duration ( $\beta=0.26,95 \%$ CI $0.1-0.4, p=0.004)$.

Pain coping (rated 0-10) was lower during perimenstrual attacks compared to nonperimenstrual attacks in women with 
MRM (adjusted mean difference $-0.2,95 \% \mathrm{CI}-0.4$ to -0.1 , $p<0.001)$, but no difference was found in women with nonMRM (adjusted mean difference $-0.05,95 \%$ CI -0.3 to 0.2 , $p=0.693$ ). Similarly, headache intensity (rated mild/ moderate/severe) was higher during perimenstrual migraine attacks in women with MRM (OR 1.6, 95\% CI 1.3-1.9, $p<$ $0.001)$, but no difference was found in women with nonMRM (OR 0.9, 95\% CI 0.6-1.2, $p=0.412$ ). A complete overview of all outcomes for perimenstrual vs nonperimenstrual attacks for women with MRM and non-MRM is presented in eTables 1 and 2 (links.lww.com/WNL/B509 and links.lww.com/WNL/B510).

\section{Subgroup Analyses: Natural Menstrual Cycle and Hormonal Contraceptives}

In women with a natural menstrual cycle, the average attack duration of perimenstrual attacks was $31 \%$ longer compared to nonperimenstrual attacks when migraine-free periods of less than 24 hours were included in the duration $(\beta=0.27$, $95 \%$ CI $0.2-0.3, p<0.001)$ and $79 \%$ longer when migraine- free periods of less than 48 hours were included in the duration $(\beta=0.58,95 \% \mathrm{CI} 0.5-0.7, p<0.001)$. In women on hormonal contraceptives, perimenstrual attacks were $60 \%$ longer when migraine-free periods of less than 24 hours were included in the duration ( $\beta=0.47,95 \%$ CI $0.3-0.7, p<0.001$ ) and $116 \%$ longer when migraine-free periods of less than 48 hours were included in the duration $(\beta=0.77,95 \% \mathrm{CI}$ $0.5-1.0, p<0.001)$.

Pain coping (rated 0-10) was lower during perimenstrual attacks compared to nonperimenstrual attacks in women with a natural menstrual cycle (adjusted mean difference $-0.2,95 \%$ CI -0.3 to $-0.05, p=0.001)$, but not in women on hormonal contraceptives (adjusted mean difference -0.6 , 95\% CI -0.9 to $-0.3, p=0.693$ ). Headache intensity (rated mild/ moderate/severe) was higher during perimenstrual migraine attacks in women with a natural menstrual cycle (OR 1.4, 95\% CI 1.2-1.6, $p<0.001)$, and even higher in women on hormonal contraceptives (OR 1.7, 95\% CI 1.2-2.6, $p=0.007$ ). A complete overview of all outcomes for perimenstrual vs

Figure 1 Flowchart of Included Participants

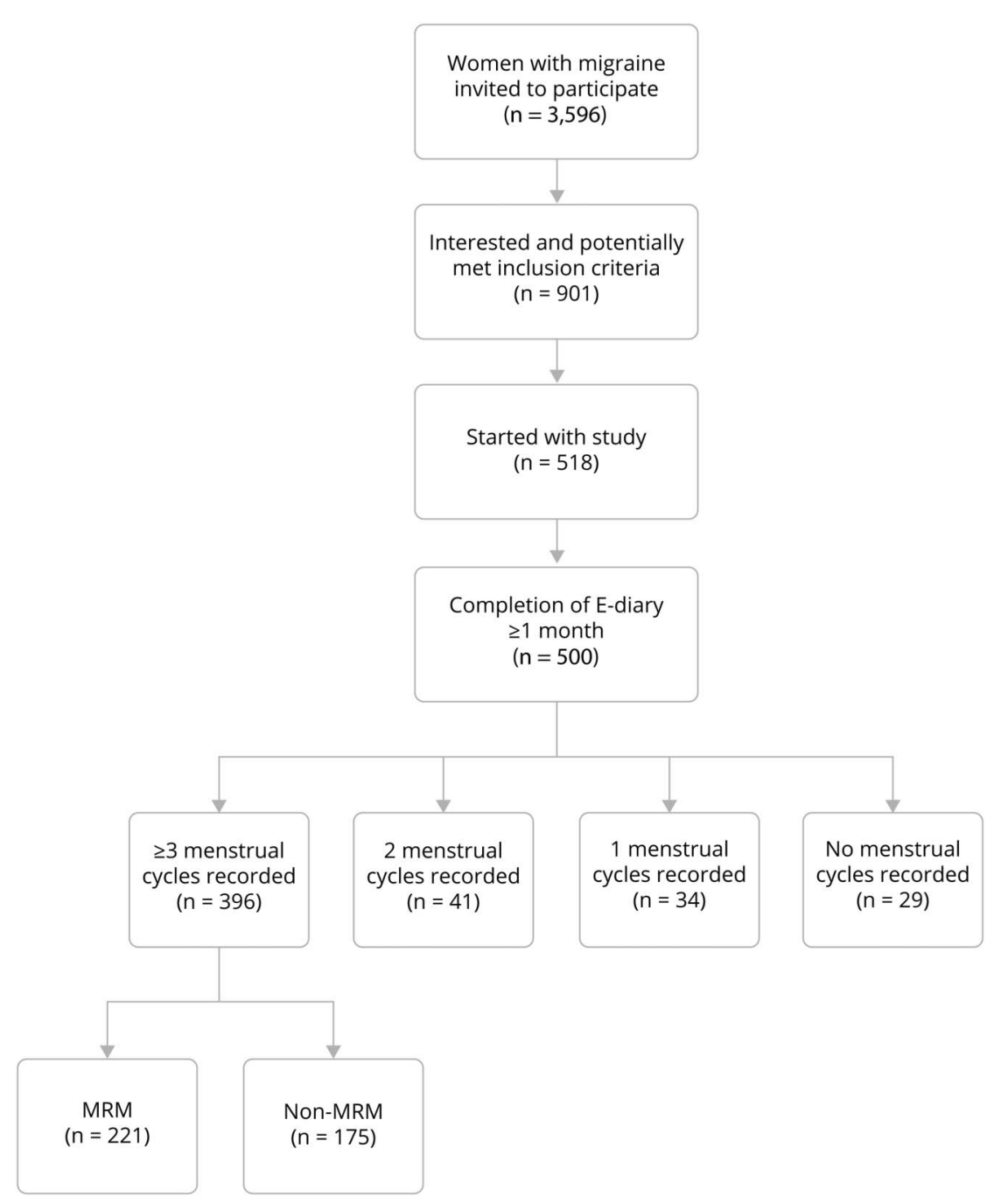

MRM = menstrually related migraine. 
Table 1 Baseline Characteristics of the Included Migraine Population

\begin{tabular}{|c|c|}
\hline & $\begin{array}{l}\text { Women with } \\
\text { migraine }(n=500)\end{array}$ \\
\hline Age, y & $40.5 \pm 8.9$ \\
\hline BMI & $24.1 \pm 4.1$ \\
\hline \multicolumn{2}{|l|}{ Migraine subtype } \\
\hline Migraine without aura & $267(53)$ \\
\hline Migraine with aura ${ }^{a}$ & $187(37)$ \\
\hline Chronic migraine $^{b}$ & $46(9)$ \\
\hline Migraine attacks/mo & $2.8 \pm 1.5$ \\
\hline Migraine $\mathrm{d} / \mathrm{mo}$ & $5.5 \pm 4.2$ \\
\hline Nonmigrainous headache $\mathrm{d} / \mathrm{mo}$ & $3.8 \pm 3.6$ \\
\hline Headache d/mo & $9.3 \pm 5.7$ \\
\hline Days with use of analgesics/mo & $4.7 \pm 4.2$ \\
\hline Days with use of triptans/mo & $2.7 \pm 2.9$ \\
\hline Use of preventive medication & $149(30)$ \\
\hline $\mathrm{MOH}^{\mathrm{c}}$ & $80(16)$ \\
\hline $\mathrm{MOH}$ and chronic migraine & $19(4)$ \\
\hline Use of combined oral contraceptives & $65(13)$ \\
\hline \multicolumn{2}{|l|}{ Menstrual cycle length, $d^{d}$} \\
\hline Women with a natural menstrual cycle & $27.5(25.5-29.5)$ \\
\hline Women using combined oral contraceptives & $28.0(28.0-28.7)$ \\
\hline
\end{tabular}

\section{Association between migraine attacks and} menstruation $(n=396)^{\mathrm{e}}$

\begin{tabular}{ll}
\hline Menstrually related migraine & $221(56)$ \\
\hline Nonmenstrual migraine & $175(44)$ \\
\hline Depressive/anxiety symptoms $(\mathrm{n}=\mathbf{4 2 2})^{\mathrm{f}}$ & \\
\hline HADS-D $\geq 8$ or CES $\geq 16$ or HADS-A $\geq 8$ & $173(41)$
\end{tabular}

Abbreviations: $\mathrm{BMI}=$ body mass index; $\mathrm{CES}=$ Center for Epidemiologic Studies Depression Scale; HADS-A = Hospital Anxiety and Depression Scale-anxiety; HADS-D $=$ Hospital Anxiety and Depression Scaledepression; $\mathrm{MOH}=$ medication overuse headache.

Values are mean $\pm S D, n(\%)$, or median (interquartile range).

${ }^{a}$ Most women with auras also experienced attacks without aura (123/187).

${ }^{b}$ Chronic migraine was defined as a mean of $\geq 15$ headache $d / m o$, of which $\geq 8$ days fulfilled criteria of a migrainous headache or triptan intake. ${ }^{21}$

' Medication overuse was defined based on the average use of acutely acting treatment (analgesics $\geq 15 \mathrm{~d} / \mathrm{mo}$ or triptans $\geq 10 \mathrm{~d} / \mathrm{mo}$ or a combination of analgesics and triptans $\geq 10 \mathrm{~d} / \mathrm{mo}$ ). ${ }^{21}$

${ }^{d}$ Menstrual cycle length was determined in $437 / 500$ patients with $\geq 2$ documented menstruations.

${ }^{\mathrm{e}}$ The association between migraine attacks and menstruation was determined in 396/500 patients with $\geq 3$ documented menstruations.

${ }^{f}$ The presence of depressive or anxiety symptoms could be determined in $422 / 500$ patients.

nonperimenstrual attacks for women with a natural menstrual cycle and women on hormonal contraceptives is presented in eTables 3 and 4 (links.lww.com/WNL/B511 and links.lww. $\mathrm{com} / \mathrm{WNL} / \mathrm{B} 512$ ).

\section{Premenstrual Syndrome}

DRSP total symptom scores were slightly higher during the midfollicular phase in women with MRM compared to nonMRM, but not during the late luteal phase (Table 4). Functional impairment scores were slightly higher in women with MRM during both the midfollicular and late luteal phase (Table 4). Prevalence of PMS was not different between women with MRM vs non-MRM (Table 4).

\section{Discussion}

This large prospective e-diary study clearly showed that perimenstrual migraine attacks have a longer duration and are more severe compared to nonperimenstrual attacks, due to a higher recurrence risk after triptan intake with no difference in 2-hours headache and pain-free response. Perimenstrual attacks are also associated with increased triptan intake. This fits with our recent systematic review and meta-analysis where we found that despite the higher drug exposure of triptans in women, they have higher headache recurrence rates, which we suggested might be due to longer attack duration related to sex hormonal changes. ${ }^{28}$ In the current study we demonstrate that this is indeed the case for perimenstrual migraine attacks as opposed to nonperimenstrual attacks. This has practical implications for migraine treatment in women.

The longer attack duration of perimenstrual attacks and higher risk of recurrence are consistent with results of previous small studies. ${ }^{8-11}$ The sex hormonal triggering effect, which is hypothetically due to estrogen changes that modulate neuronal brain excitability and the trigeminovascular system, ${ }^{4-6}$ seems to result in a longer attack duration with failure of effectiveness after an initial adequate triptan response. Thus, in contrast to what has been suggested about acute migraine treatments that would be less effective for perimenstrual migraine attacks, ${ }^{8}$ our e-diary study showed similar 2-hour response rates after triptan use, but higher recurrence rates. This finding fits our expectations since we recently showed that women have a higher triptan exposure compared to men and similar 2-hour response rates. ${ }^{28}$ The prolonged attack duration of perimenstrual migraine attacks in our study was found in a population that consisted of women with natural menstrual cycles and women using combined oral contraceptives. We have performed subgroup analyses comparing perimenstrual and nonperimenstrual attacks in women with natural menstrual cycles and women on hormonal contraceptives and found longer perimenstrual attack duration in both groups. This is in line with a small diary-based study that specifically studied pill use in 28 women and also found that attacks during the hormone-free interval lasted longer. ${ }^{29}$ In addition, we have performed subgroup analyses comparing women diagnosed with MRM and women with non-MRM. These subgroup analyses indicate that, in general, differences between perimenstrual and nonperimenstrual attacks are more pronounced in women with MRM than in women with non-MRM. 
A

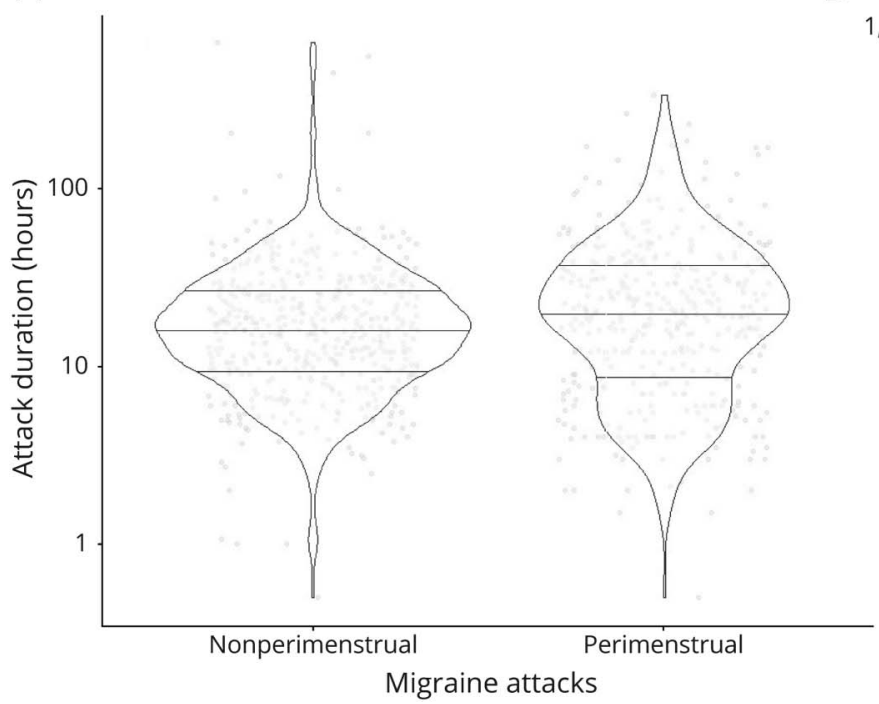

B

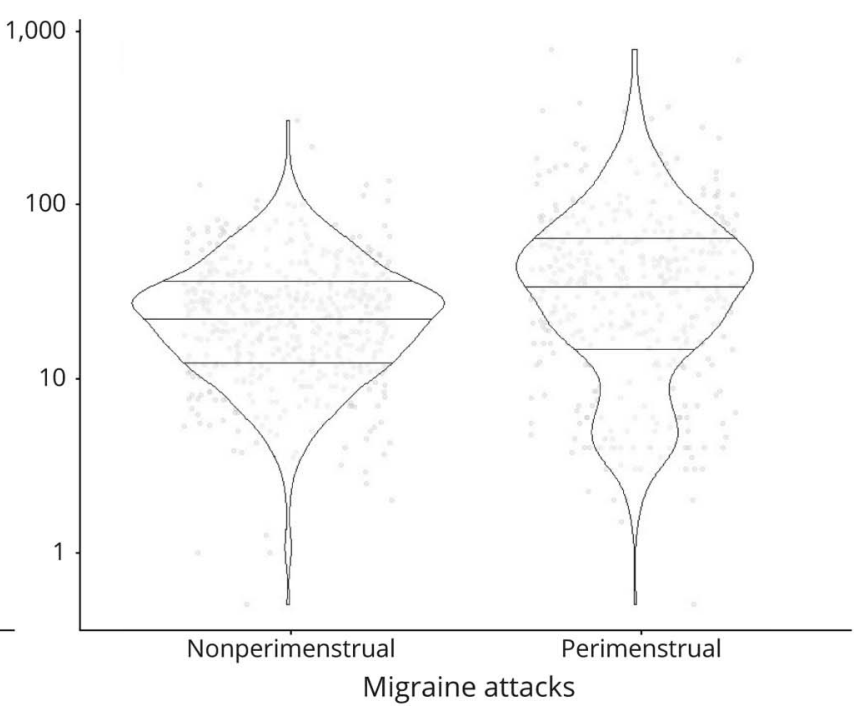

(A) Duration when migraine-free periods of less than 24 hours are included. (B) Duration when migraine-free periods of less than 48 hours are included. Intraindividual mean duration was calculated for perimenstrual attacks and nonperimenstrual attacks to account for the correlation between migraine attacks within the same participant.

Cortical spreading depression (CSD), which is thought to be the underlying mechanism of the migraine aura, is also suggested to be affected by estrogen levels. High estrogen levels were shown to increase CSD susceptibility, whereas estrogen withdrawal and low estrogen levels appeared to decrease the risk for $\mathrm{CSD}^{30-32}$ which may explain why perimenstrual migraine attacks are less likely to be associated with aura in women with MRM. The observed more pronounced photophobia during perimenstrual migraine attacks seems noteworthy in that light because previous studies suggested photophobia to be associated with visual aura. ${ }^{33,34} \mathrm{~A}$ greater visual cortex hyperexcitability in migraine with aura may induce abnormal processing of light sensitivity and may be the link between symptoms of photophobia and CSD susceptibility. ${ }^{35-38}$

Women with MRM did not have a higher PMS prevalence compared to women with non-MRM, in contrast to what some small diary-based pilot studies suggested. ${ }^{13,39-41}$ The prevalence of PMS in our large cohort of women with migraine is comparable to the prevalence in the general population, which ranges between $5 \%$ and $20 \%{ }^{18}$ Our finding corresponds with previous studies reporting PMS in $10 \%-30 \%$ of women with migraine and we did not find a difference in PMS between women with and without MRM. $^{13-15,42}$ However, as there is important overlap in symptomology between PMS and the prodromal phase of migraine it is conceivable that women with MRM are less likely to differentiate between these 2 phenomena. Importantly, we did find slightly higher PMS symptom scores and functional impairment scores in women with MRM compared to women with non-MRM. Previously, the potential comorbidity between PMS and migraine was suggested to be due to the involvement of serotonin in both disorders and cyclical changes in its levels resulting from estrogen fluctuations. ${ }^{24,43}$

Table 2 Descriptive Statistics on the Continuous Outcomes Duration (Hours) and Pain Coping (0-10, Lower Score Means Less Coping) for Perimenstrual and Nonperimenstrual Migraine Attacks

\begin{tabular}{lll}
\hline & Perimenstrual attacks $(\mathbf{n}=\mathbf{9 9 8})$ & Nonperimenstrual attacks $(\mathbf{n}=\mathbf{4 0 9 7})$ \\
\hline Duration, $\mathbf{h}$, including $\mathbf{2 4}$ hours migraine-free & $20.0(8.5-37.0)$ & $16.1(9.7-26.6)$ \\
\hline Duration, $\mathbf{h}$, including $\mathbf{4 8}$ hours migraine-free & $35.4(16.0-63.0)$ & $22.7(12.3-35.2)$ \\
\hline Pain coping score (0-10 scale) & $5.1 \pm 1.6$ & $5.4 \pm 1.3$ \\
\hline
\end{tabular}

Values are median (interquartile range) or mean \pm SD. Intraindividual means were calculated for perimenstrual attacks and nonperimenstrual attacks prior to group calculations to account for the correlation between migraine attacks within the same participant. Numbers of attacks included in the analyses on duration when migraine-free periods of less than 48 hours were included in the duration were lower than presented in the Table $(n=894$ and $n=3,253$, respectively). The adjusted mean difference on pain coping presented in the text is calculated with a linear mixed effects model corrected for potential confounders and therefore slightly deviates from the result presented in this table. 


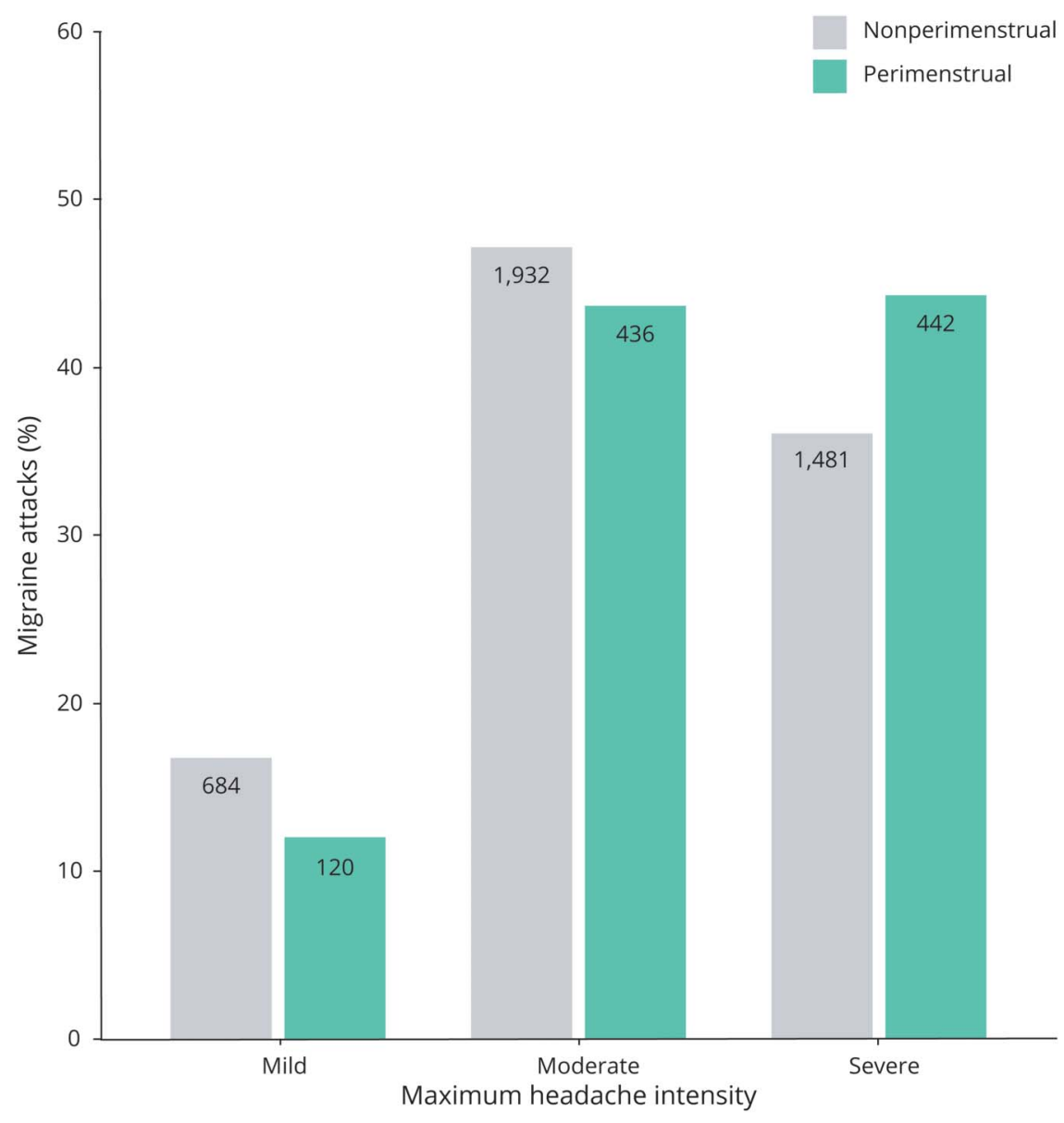

However, growing evidence suggests that affective symptoms of PMS reflect suboptimal GABA(A) receptor sensitivity to fluctuating levels of the positive modulator allopregnanolone, ${ }^{44}$ which is a neuroactive metabolite of progesterone with an inhibitory effect on neuronal excitability. ${ }^{45}$ Reduced levels of allopregnanolone have been associated with the development of depressive disorders and menstrual cyclerelated disorders such as PMS. ${ }^{46}$ However, conflicting results were observed in small studies for serum allopregnanolone concentrations between women with and without migraine. $^{47,48}$

Strengths of the current study include the large sample of well-defined female patients with migraine and the use of our self-developed and validated time-locked e-diary with an automated algorithm differentiating headache and migraine days based on detailed characteristics according to ICHD-3 criteria. ${ }^{22}$ In almost all currently available daily E-diaries, migraine days are defined based on whether the patient reports a day as a migraine or headache day just stating yes or no. Missing e-diary days were considered free of symptoms, which is expected to have a negligible influence on our results since e-diary adherence was very high and patients report that they are more likely to register days with complaints than days without complaints. The Leiden E-headache diary is timelocked, meaning that no adjustments can be made after completion of a day or the diary is locked when it is not filled out after a predefined time period, which prevents patients from changing their input. The study also has some limitations. Firstly, we defined recurrences only after the intake of triptans, and not after intake of painkillers or nonsteroidal anti-inflammatory drugs, as we considered this to be more robust. However, in the definition of migraine attack duration, migraine-free periods of 24 hours or 48 hours were included regardless of the intake and effectivity of acutely acting medication. Secondly, women with chronic migraine were not excluded, although it might be disputed whether women with chronic migraine can be diagnosed with MRM due to the high likelihood of chance diagnosis. ${ }^{49}$ We did correct for chronic migraine in our analyses by adding it as a covariate. Furthermore, we performed a sensitivity analysis for our primary outcome by excluding women with chronic migraine and we found similar results (data not shown). We therefore expect the inclusion of women with chronic migraine to have a negligible influence on our results. Thirdly, we performed subgroup analyses by diagnosis (MRM and non-MRM), and 
Table 3 Prevalence of Ordinal and Binary Outcomes Separately for Perimenstrual and Nonperimenstrual Migraine Days With Corresponding Results of Mixed Effects Models

\begin{tabular}{|c|c|c|c|c|}
\hline & $\begin{array}{l}\text { Perimenstrual migraine } \\
d(n=2272)\end{array}$ & $\begin{array}{l}\text { Nonperimenstrual migraine } \\
d(n=7399)\end{array}$ & Adjusted OR $(95 \% \mathrm{Cl})$ & Adjusted $p$ value \\
\hline Photophobia & 86.3 & 82.9 & $1.3(1.2-1.4)$ & $<0.001$ \\
\hline Phonophobia & 82.7 & 79.5 & $1.2(1.1-1.4)$ & $<0.001$ \\
\hline Nausea & 63.6 & 60.9 & $1.0(0.9-1.1)$ & 0.850 \\
\hline Vomiting & 7.2 & 7.7 & $0.9(0.7-1.1)$ & 0.205 \\
\hline Aura symptoms & 7.3 & 9.4 & $0.8(0.6-1.0)$ & 0.054 \\
\hline Use of analgesics & 44.8 & 41.9 & $1.3(0.7-2.2)$ & 0.370 \\
\hline Use of triptans & 53.7 & 48.8 & $1.2(1.1-1.4)$ & 0.004 \\
\hline 2-hour headache response & 61.2 & 62.4 & $0.9(0.8-1.1)$ & 0.414 \\
\hline 2-hour pain-free response & 29.7 & 29.2 & $1.0(0.8-1.2)$ & 0.993 \\
\hline Recurrence $<24$ hours & 16.3 & 8.3 & $2.4(2.0-2.9)$ & $<0.001$ \\
\hline Recurrence $<48$ hours & 17.2 & 7.5 & $2.8(2.4-3.3)$ & $<0.001$ \\
\hline
\end{tabular}

Abbreviations: $\mathrm{Cl}=$ confidence interval; $\mathrm{OR}=$ odds ratio.

Values are percentages. The associated symptoms photophobia, phonophobia, nausea, and vomiting were rated on an ordinal scale (no-mild-moderatesevere); all other outcomes presented in the Table are rated on a binary scale (no-yes). To obtain frequency numbers on associated symptoms, a comparison was made between negative replies and positive replies (i.e., mild, moderate, or severe were rated as yes). ORs for associated symptoms were calculated based on the ordinal results with ordinal logistic mixed effects models and for all other outcomes with logistic mixed effects models, adjusted for chronic migraine, medication overuse, and the use of combined oral contraceptives. Analgesics use was in addition corrected for use because of menstrual pain. Prevalence of 2-hour responses is calculated based on migraine days with triptan intake (respectively $n=1,244$ and $n=3,699$ days). Recurrence is calculated based on days with triptan intake including respectively 24 hours and 48 hours.

in addition, by contraceptive use (women using combined oral contraceptives and women with a natural menstrual cycle). The study was not powered to detect differences within these subgroups and the number of perimenstrual attacks in women with non-MRM was small. Therefore, nonsignificant $p$ values should be interpreted cautiously. No subgroup analyses were performed for women using preventive medication, as only a minority of included women used preventive medication and type and dosage differed between these patients. Earlier research in women treated with topiramate suggests that perimenstrual and nonperimenstrual attacks respond similarly to preventive treatment. ${ }^{50}$ Lastly, the lack of uniformity in the interpretation of what is substantial PMS in combination with the fact that research on PMS in women with migraine is further complicated by overlapping symptomatology of PMS, the premonitory phase of migraine attacks, and depression and anxiety, which are strongly associated with migraine, ${ }^{25-27}$ made us choose to adjust DRSP, ACOG, and DSM-IV criteria into a definition that we considered clinically relevant for women with migraine. ${ }^{23}$

Table 4 Crude Data on Daily Record of Severity of Problems Scale Scores During the Late Luteal Phase and Midfollicular Phase of the Menstrual Cycle and Premenstrual Syndrome

\begin{tabular}{|c|c|c|c|c|}
\hline & $\begin{array}{l}\text { Total population } \\
(\mathrm{n}=344)\end{array}$ & $\begin{array}{l}\text { Menstrually related migraine } \\
(n=187)\end{array}$ & $\begin{array}{l}\text { Nonmenstrual migraine } \\
(n=157)\end{array}$ & $p$ Value \\
\hline Luteal total symptom score & $31.4(26.0-38.8)$ & $31.8(27.4-39.6)$ & $30.4(24.9-37.6)$ & 0.053 \\
\hline Follicular total symptom score & $28.5(24.6-35.2)$ & $28.8(25.1-38.5)$ & $27.4(23.8-34.5)$ & 0.012 \\
\hline Luteal total impairment score & $4.3(3.5-6.2)$ & $4.4(3.7-6.4)$ & $4.1(3.3-6.0)$ & 0.021 \\
\hline Follicular total impairment score & $4.4(3.5-6.0)$ & $4.5(3.6-6.5)$ & $4.0(3.3-5.7)$ & 0.013 \\
\hline Premenstrual syndrome diagnosis & $44(13)$ & $20(11)$ & $24(15)$ & 0.268 \\
\hline
\end{tabular}

Values are median (interquartile range) or $\mathrm{n}(\%)$.

Women with migraine who were not using combined oral contraceptives and with at least 3 registered menstrual cycles were included. Daily Record of Severity of Problem total symptom score ranges from 21 to 126; total functional impairment score ranges from 3 to 18 . The following criteria needed to be met for premenstrual syndrome: (1) 30\% higher mean total symptom score in late luteal phase compared to midfollicular phase; (2) higher mean total functional impairment score in late luteal phase compared to midfollicular phase. Group differences on symptom scores and impairment scores were calculated with Wilcoxon rank-sum tests and on premenstrual syndrome diagnoses with a $\chi^{2}$ test. 
Therefore, women with depressive or anxiety symptoms were not excluded and premenstrual symptoms did not have to remit completely following onset of menstruation in order to meet our definition of PMS, as such symptoms may also be attributed to (the premonitory phase of) a migraine attack.

Physicians treating women with MRM should be aware of a long duration of perimenstrual attacks with a high risk of recurrence. Although women are more likely to report adverse events after the intake of triptans than men, ${ }^{28}$ they often need to take triptans repeatedly during their perimenstrual attacks. Consequently, women with MRM are at increased risk for medication overuse. Physicians should be encouraged to prescribe preventive treatments in women with disabling perimenstrual migraine attacks to diminish duration and severity of attacks, because this may prevent the need for these women to use triptans during multiple subsequent days. In addition, physicians should consider prescribing long-acting triptans such as eletriptan or frovatriptan for the acute treatment of migraine attacks, aiming to reduce the risk of recurrence. Alternatively, long-acting nonsteroidal antiinflammatory drugs such as etoricoxib or naproxen could be added to a triptan with a short half-life time such as sumatriptan or rizatriptan. The intake of etoricoxib or naproxen should be timed based on the expected timing of recurrence (e.g., before going to sleep if the recurrences normally are the next morning or on awakening). Short-term prophylaxis with frovatriptan or etoricoxib starting 1-2 days prior to the onset of menstruation with a maximum of 7 subsequent days should only be considered in women with pure menstrual migraine, because it can easily induce medication overuse in women who have additional attacks at other times of the cycle.

The long duration of perimenstrual migraine attacks with a high risk of recurrence highlights the need to improve understanding of the role of sex hormones in the provocation of attacks in women with migraine. Ultimately, this knowledge will contribute to the development of an urgently needed female-specific prophylactic treatment intervening with sex hormones. To begin with, the potential efficacy of existing hormonal treatments, such as combined oral contraceptives, in the prevention of migraine attacks should be clarified (WHAT! Study [ClinicalTrials.gov NCT04007874]). In addition, future large-scale daily e-diary studies are needed to assess symptoms belonging to the premonitory phase in women with migraine and to determine their contribution in the prediction of an upcoming migraine attack.

\section{Study Funding}

Supported by The Netherlands Organization for Health Research and Development (ZonMw nr. 849200007) and the Dutch Brain Foundation (nr. HA2017.01.05).

\section{Disclosure}

A. MaassenVanDenBrink reports consultancy or industry support from Novartis, Lilly and Teva, and Allergan and independent support from the Netherlands Organization for
Scientific Research and the Dutch Heart \& Brain Foundations. G.M. Terwindt reports consultancy or industry support from Novartis, Lilly and Teva, and Allergan, and independent support from the Netherlands Organization for Scientific Research and the Dutch Heart \& Brain Foundations. D.S. van Casteren reports independent support from the Netherlands Organization for Health Research and Development and the Dutch Brain Foundation. I.E. Verhagen reports independent support from the Netherlands Organization for Health Research and Development and the Dutch Brain Foundation. B.W.H. van der Arend and E.W. van Zwet declare no disclosures relevant to the manuscript. Go to Neurology.org/N for full disclosures.

\section{Publication History}

Received by Neurology January 1, 2021. Accepted in final form August 5, 2021.

\section{Appendix Authors}

\begin{tabular}{|c|c|c|}
\hline Name & Location & Contribution \\
\hline $\begin{array}{l}\text { Daphne S. van } \\
\text { Casteren, MD, PhD }\end{array}$ & $\begin{array}{l}\text { Leiden University } \\
\text { Medical Center, } \\
\text { Leiden and Erasmus } \\
\text { Medical Center, } \\
\text { Rotterdam }\end{array}$ & $\begin{array}{l}\text { Study concept and } \\
\text { design; acquisition of } \\
\text { data; analysis and } \\
\text { interpretation of data; } \\
\text { drafting the manuscript }\end{array}$ \\
\hline Iris E. Verhagen, MD & $\begin{array}{l}\text { Leiden University } \\
\text { Medical Center, } \\
\text { Leiden and Erasmus } \\
\text { Medical Center, } \\
\text { Rotterdam }\end{array}$ & $\begin{array}{l}\text { Analysis and } \\
\text { interpretation of data; } \\
\text { revising the manuscript }\end{array}$ \\
\hline $\begin{array}{l}\text { Britt W.H. van der } \\
\text { Arend, MD }\end{array}$ & $\begin{array}{l}\text { Leiden University } \\
\text { Medical Center, } \\
\text { Leiden and Erasmus } \\
\text { Medical Center, } \\
\text { Rotterdam }\end{array}$ & $\begin{array}{l}\text { Acquisition of data; } \\
\text { revising the manuscript }\end{array}$ \\
\hline Erik W. van Zwet, PhD & $\begin{array}{l}\text { Leiden University } \\
\text { Medical Center }\end{array}$ & $\begin{array}{l}\text { Analysis and } \\
\text { interpretation of data; } \\
\text { revising the manuscript }\end{array}$ \\
\hline $\begin{array}{l}\text { Antoinette } \\
\text { MaassenVanDenBrink, } \\
\text { PhD }\end{array}$ & $\begin{array}{l}\text { Erasmus Medical } \\
\text { Center, Rotterdam }\end{array}$ & $\begin{array}{l}\text { Study concept and } \\
\text { design; interpretation } \\
\text { of data; revising the } \\
\text { manuscript }\end{array}$ \\
\hline $\begin{array}{l}\text { Gisela M. Terwindt, MD, } \\
\text { PhD }\end{array}$ & $\begin{array}{l}\text { Leiden University } \\
\text { Medical Center }\end{array}$ & $\begin{array}{l}\text { Study concept and } \\
\text { design; interpretation } \\
\text { of data; revising the } \\
\text { manuscript }\end{array}$ \\
\hline
\end{tabular}

\section{References}

1. Macgregor EA. Headache in pregnancy. Continuum. 2014;20(1):128-147.

2. MacGregor EA. Migraine headache in perimenopausal and menopausal women. Curr Pain Headache Rep. 2009;13(5):399-403.

3. van Casteren DS, Verhagen IE, Onderwater GLJ, MaassenVanDenBrink A, Terwindt GM. Sex differences in prevalence of migraine trigger factors: a cross-sectional study. Cephalalgia. 2021;41(6):643-648.

4. Kelly MJ, Rønnekleiv OK. Control of CNS neuronal excitability by estrogens via membrane-initiated signaling. Mol Cell Endocrinol. 2009(1-2);308:17-25.

5. Lee AW, Kyrozis A, Chevaleyre V, et al. Estradiol modulation of phenylephrineinduced excitatory responses in ventromedial hypothalamic neurons of female rats. Proc Natl Acad Sci USA. 2008;105(20):7333-7338.

6. Finocchi C, Ferrari M. Female reproductive steroids and neuronal excitability. Neurol Sci. 2011;32(suppl 1):S31-S35.

7. Pavlovic JM, Allshouse AA, Santoro NF, et al. Sex hormones in women with and without migraine: evidence of migraine-specific hormone profiles. Neurology. 2016; 87(1):49-56. 
8. Pinkerman B, Holroyd K. Menstrual and nonmenstrual migraines differ in women with menstrually-related migraine. Cephalalgia. 2010;30(10):1187-1194.

9. Stewart WF, Lipton RB, Chee E, Sawyer J, Silberstein SD. Menstrual cycle and headache in a population sample of migraineurs. Neurology. 2000;55(10):1517-1523.

10. Vetvik KG, Benth JŠ, MacGregor EA, Lundqvist C, Russell MB. Menstrual versus nonmenstrual attacks of migraine without aura in women with and without menstrual migraine. Cephalalgia. 2015;35(14):1261-1268.

11. MacGregor EA, Victor TW, Hu X, et al. Characteristics of menstrual vs nonmenstrual migraine: a post hoc, within-woman analysis of the usual-care phase of a nonrandomized menstrual migraine clinical trial. Headache. 2010;50(4):528-538.

12. Karsan N, Goadsby PJ. Imaging the premonitory phase of migraine. Front Neurol. 2020;11:140.

13. Facchinetti F, Neri I, Martignoni E, Fioroni L, Nappi G, Genazzani AR. The association of menstrual migraine with the premenstrual syndrome. Cephalalgia. 1993; 13(6):422-425

14. Mattsson P. Hormonal factors in migraine: a population-based study of women aged 40 to 74 years. Headache. 2003;43(1):27-35.

15. Fragoso YD, Guidoni AC, de Castro LB. Characterization of headaches in the premenstrual tension syndrome. Arq Neuropsiquiatr. 2009;67(1):40-42.

16. Yamada K. High prevalence of menstrual migraine comorbidity in patients with premenstrual dysphoric disorder: retrospective survey. Cephalalgia. 2016;36(3): 294-295.

17. Endicott J, Nee J, Harrison W. Daily Record of Severity of Problems (DRSP): reliability and validity. Arch Womens Ment Health. 2006;9(1):41-49.

18. Yonkers KA, O’Brien PM, Eriksson E. Premenstrual syndrome. Lancet. 2008; 371(9619):1200-1210.

19. Launer LJ, Terwindt GM, Ferrari MD. The prevalence and characteristics of migraine in a population-based cohort: the GEM study. Neurology. 1999;53(3):537-542.

20. van Oosterhout WP, Weller CM, Stam AH, et al. Validation of the web-based LUMINA questionnaire for recruiting large cohorts of migraineurs. Cephalalgia. 2011; 31(13):1359-1367.

21. Headache Classification Committee of the International Headache Society (IHS) The International Classification of Headache Disorders, 3rd edition. Cephalalgia. 2018;38(1):1-211.

22. van Casteren DS, Verhagen IE, de Boer I, et al. E-diary use in clinical headache practice: a prospective observational study. Cephalalgia. 2021:3331024211010306.

23. O'Brien PM, Bäckström T, Brown C, et al. Towards a consensus on diagnostic criteria, measurement and trial design of the premenstrual disorders: the ISPMD Montreal consensus. Arch Womens Ment Health. 2011;14(1):13-21.

24. Rapkin A. A review of treatment of premenstrual syndrome \& premenstrual dysphoric disorder. Psychoneuroendocrinology. 2003;28(suppl 3):39-53.

25. Breslau N, Lipton RB, Stewart WF, Schultz LR, Welch KM. Comorbidity of migraine and depression: investigating potential etiology and prognosis. Neurology. 2003; 60(8):1308-1312

26. Stam AH, de Vries B, Janssens AC, et al. Shared genetic factors in migraine and depression: evidence from a genetic isolate. Neurology. 2010;74(4):288-294.

27. Victor TW, Hu X, Campbell J, White RE, Buse DC, Lipton RB. Association between migraine, anxiety and depression. Cephalalgia. 2010;30(5):567-575.

28. van Casteren DS, Kurth T, Danser AHJ, Terwindt GM, MaassenVanDenBrink A. Sex differences in response to triptans: a systematic review and meta-analysis. Neurology. 2021;96(4):162-170.

29. Merki-Feld GS, Caveng N, Speiermann G, MacGregor EA. Migraine start, course and features over the cycle of combined hormonal contraceptive users with menstrual migraine: temporal relation to bleeding and hormone withdrawal: a prospective diarybased study. J Headache Pain. 2020;21(1):81.
30. Chauvel V, Multon S, Schoenen J. Estrogen-dependent effects of 5-hydroxytryptophan on cortical spreading depression in rat: modelling the serotonin-ovarian hormone interaction in migraine aura. Cephalalgia. 2018;38(3):427-436.

31. Eikermann-Haerter K, Dileköz E, Kudo C, et al. Genetic and hormonal factors modulate spreading depression and transient hemiparesis in mouse models of familial hemiplegic migraine type 1. J Clin Invest. 2009;119(1):99-109.

32. Brennan KC, Romero Reyes M, López Valdés HE, Arnold AP, Charles AC. Reduced threshold for cortical spreading depression in female mice. Ann Neurol. 2007;61(6): 603-606.

33. Hayne DP, Martin PR. Relating photophobia, visual aura, and visual triggers of headache and migraine. Headache. 2019;59(3):430-442.

34. Munjal S, Singh P, Reed ML, et al. Most bothersome symptom in persons with migraine: results from the Migraine in America Symptoms and Treatment (MAST) study. Headache. 2020;60(2):416-429.

35. Datta R, Aguirre GK, Hu S, Detre JA, Cucchiara B. Interictal cortical hyperresponsiveness in migraine is directly related to the presence of aura. Cephalalgia. 2013;33(6):365-374.

36. Tedeschi G, Russo A, Conte F, et al. Increased interictal visual network connectivity in patients with migraine with aura. Cephalalgia. 2016;36(2):139-147.

37. Noseda R, Burstein R. Migraine pathophysiology: anatomy of the trigeminovascular pathway and associated neurological symptoms, cortical spreading depression, sensitization, and modulation of pain. Pain. 2013;154(suppl 1):S44-S53.

38. Boulloche N, Denuelle M, Payoux P, Fabre N, Trotter Y, Géraud G. Photophobia in migraine: an interictal PET study of cortical hyperexcitability and its modulation by pain. J Neurol Neurosurg Psychiatry. 2010;81(9):978-984.

39. Beckham JC, Krug LM, Penzien DB, et al. The relationship of ovarian steroids, headache activity and menstrual distress: a pilot study with female migraineurs. Headache. 1992;32(6):292-297.

40. Goldberg J, Wolf A, Silberstein S, et al. Evaluation of an electronic diary as a diagnostic tool to study headache and premenstrual symptoms in migraineurs. Headache. 2007; 47(7):384-396.

41. Martin VT, Wernke S, Mandell K, et al. Symptoms of premenstrual syndrome and their association with migraine headache. Headache. 2006;46(1):125-137.

42. Vetvik KG, MacGregor EA, Lundqvist C, Russell MB. Symptoms of premenstrual syndrome in female migraineurs with and without menstrual migraine. J Headache Pain. 2018;19(1):97.

43. Rybaczyk LA, Bashaw MJ, Pathak DR, Moody SM, Gilders RM, Holzschu DL. An overlooked connection: serotonergic mediation of estrogen-related physiology and pathology. BMC Womens Health. 2005;5:12.

44. Hantsoo L, Epperson CN. Allopregnanolone in premenstrual dysphoric disorder (PMDD): evidence for dysregulated sensitivity to GABA-A receptor modulating neuroactive steroids across the menstrual cycle. Neurobiol Stress. 2020;12:100213.

45. Reddy DS. Neurosteroids: endogenous role in the human brain and therapeutic potentials. Prog Brain Res. 2010;186:113-137.

46. Bernardi F, Pluchino N, Begliuomini S, et al. Disadaptive disorders in women: allopregnanolone, a sensitive steroid. Gynecol Endocrinol. 2004;19(6):344-353.

47. Koverech A, Cicione C, Lionetto L, et al. Migraine and cluster headache show impaired neurosteroids patterns. J Headache Pain. 2019;20(1):61.

48. Rustichelli C, Bellei E, Bergamini S, et al. Serum levels of allopregnanolone, progesterone and testosterone in menstrually-related and postmenopausal migraine: a cross-sectional study. Cephalalgia. 2020;40(12):1355-1362.

49. Barra M, Dahl FA, MacGregor EA, Vetvik KG. Identifying menstrual migraine: improving the diagnostic criteria using a statistical method. J Headache Pain. 2019;20(1):95.

50. Allais G, Sanchez del Rio M, Diener HC, et al. Perimenstrual migraines and their response to preventive therapy with topiramate. Cephalalgia. 2011;31(2):152-160. 


\section{Neurology}

Comparing Perimenstrual and Nonperimenstrual Migraine Attacks Using an e-Diary

Daphne S. van Casteren, Iris E. Verhagen, Britt W.H. van der Arend, et al.

Neurology 2021;97;e1661-e1671 Published Online before print September 7, 2021

DOI 10.1212/WNL.0000000000012723

This information is current as of September 7, 2021

\begin{tabular}{|c|c|}
\hline $\begin{array}{l}\text { Updated Information \& } \\
\text { Services }\end{array}$ & $\begin{array}{l}\text { including high resolution figures, can be found at: } \\
\text { http://n.neurology.org/content/97/17/e1661.full }\end{array}$ \\
\hline References & $\begin{array}{l}\text { This article cites } 49 \text { articles, } 8 \text { of which you can access for free at: } \\
\text { http://n.neurology.org/content/97/17/e1661.full\#ref-list-1 }\end{array}$ \\
\hline Citations & $\begin{array}{l}\text { This article has been cited by } 1 \text { HighWire-hosted articles: } \\
\text { http://n.neurology.org/content/97/17/e1661.full\#\#otherarticles }\end{array}$ \\
\hline Subspecialty Collections & $\begin{array}{l}\text { This article, along with others on similar topics, appears in the } \\
\text { following collection(s): } \\
\text { Migraine } \\
\text { http://n.neurology.org/cgi/collection/migraine }\end{array}$ \\
\hline Permissions \& Licensing & $\begin{array}{l}\text { Information about reproducing this article in parts (figures,tables) or in } \\
\text { its entirety can be found online at: } \\
\text { http://www.neurology.org/about/about_the_journal\#permissions }\end{array}$ \\
\hline Reprints & $\begin{array}{l}\text { Information about ordering reprints can be found online: } \\
\text { http://n.neurology.org/subscribers/advertise }\end{array}$ \\
\hline
\end{tabular}

Neurology ${ }^{\circledR}$ is the official journal of the American Academy of Neurology. Published continuously since 1951, it is now a weekly with 48 issues per year. Copyright Copyright ( 2021 The Author(s). Published by Wolters Kluwer Health, Inc. on behalf of the American Academy of Neurology.. All rights reserved. Print ISSN: 0028-3878. Online ISSN: 1526-632X.

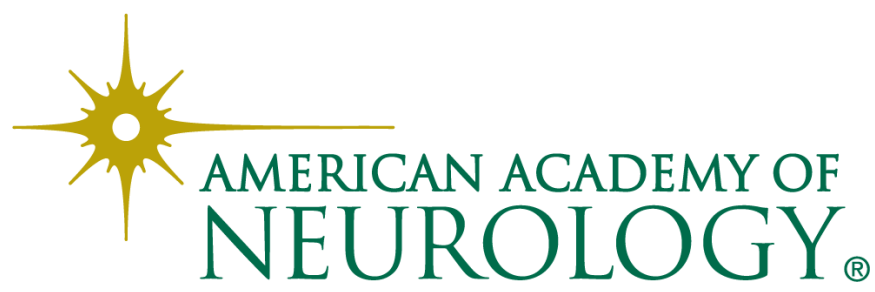

